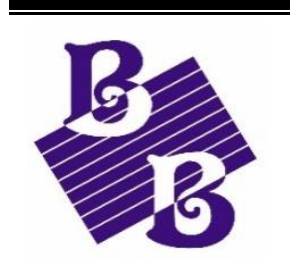

BioBacta

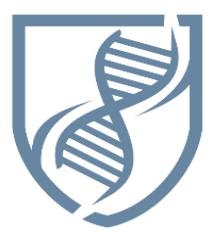

Journal of Bioscience and Applied Research

www.jbaar.org

\title{
Immunopathogenic mechanisms of primary glomerulonephritis
}

\section{L.M karzakova, N.V Zhuravleva, A.Y Abdelgafur, S.I Kudryashov, A.M Nawar}

Chuvash State University named after I. N. Ulyanov "Ministry of Education and Science of the Russian Federation, 428015, Cheboksary, Russia

- For correspondence: Louise M. Karzakova, Doctor of Medical Sciences, Head of the department of internal diseases, Chuvash state university; 15, Moscow avenue, Cheboksary, 428015, Russian Federation.

\section{Information about authors:}

- Karzakova Louise: Doctor of Medical Sciences, Professor, Head of Internal Diseases Department, Chuvash State University, Cheboksary, Russia. Email: (luizak58@mail.ru)

- Zhuravleva Nadezhda: Candidate of Medical Sciences, Associate Professor of Internal Medicine Department, Chuvash State University, Cheboksary, Russia. Email: (Zhuravlevanv@mail.ru).

- Ahmed Yousry Abdelgafur Omar: Candidate of Medical Sciences, Head of Drug Therapy Department, Republican Clinical Oncological Dispensary of the Ministry of Health of Chuvashia, Cheboksary, Russia.

Email: (abdelgafur75@mail.ru)

- Kudryashov Sergey: Candidate of Medical Sciences, Assistant Lecturer of Internal Diseases Department, Chuvash State University, Cheboksary, Russia Email: (medicpro21@mail.ru)

- Adel Mohamed Nawar: Email: (adelnawar15@gmail.com)

DOI: $10.21608 /$ jbaar.2021.175196

\section{Abstract:}

The low effectiveness of the existing ways of treatment of glomerulonephritis (GN) requires the development of new treatment methods and profound studying of mechanisms of development of (GN). A review of modern literature data indicates a relationship between the development of $(\mathrm{GN})$ with infection and activation of various components of the immune response. Pathogen-associated molecular patterns of infectious pathogens act as "danger signals" that activate Toll-like receptors of innate immune cells, as a result, a cascade of intracellular chain reactions is triggered, causing the production of growth factors and cytokines. The cytokine environment determines the pathway of differentiation of $\left(\mathrm{CD} 4^{+}\right)$helper cells into (Th1), (Th2), (Th17), and regulatory T cells $\left(\mathrm{T}_{\mathrm{reg}}\right)$. According to published data, a key link in the $(\mathrm{GN})$ immunopathogenesis is an imbalance in the ratio of the activity of subpopulations of $\mathrm{T}$ helper cells, manifesting inhibition activity of ( $\mathrm{T}$ reg) on a background of activation of effector cells ( $\mathrm{T}$ eff $)$ - (Th1), (Th2), (Th17). The activity of (Th1), (Th17)-cells are realized in the cellular mechanisms of the immunopathogenesis of (GN), while (Th2)-cells provide activation of the humoral component of adaptive immunity and the production of antibodies involved in the formation of immune complexes (ICs). This is a general scheme of the immunopathogenesis of $(\mathrm{GN})$, which has specific variations depending on the clinical and morphological form of $(\mathrm{GN})$. In post-infectious $(\mathrm{GN})$, the activation of the humoral link of adaptive immunity with the formation of (ICs) and their subsequent deposition in the capillaries of the glomeruli comes to the fore. A feature of the immune complex process in patients with ( $\operatorname{IgA})$ nephropathy is the formation of "nephritogenic" ICs containing abnormal (IgA) (with impaired glycosylation of the IgA molecule) and anti- 
glycan antibodies. (ICs) isolated from patients with membranous nephropathy contain the podocyte receptor of phospholipase A2 (PLA 2 R) and anti- (PLA 2 R) autoantibodies belonging to ( $\operatorname{IgG} 4$ ). The central link in the immunopathogenesis of minimal changes in nephropathy is the development of an immediate hypersensitivity reaction. The prevalence of activation of the cellular mechanism of adaptive immunity acts as the main mechanism for the development of focal segmental nephrosclerosis.

Keywords: Glomerulonephritis; innate immunity; cytokines; ( $\left.\mathrm{T}_{\text {reg }}\right)$; $\left(\mathrm{T}_{\text {eff }}\right)$.

\section{Introduction:}

The immunological aspects of the pathogenesis of glomerulonephritis (GN) have been the focus of attention of the world medical community in recent years. Immunological developments are associated with the solution of such clinical problems as early diagnosis, pathogenetically based therapy, and prognosis of the course of $(\mathrm{GN})(1)$. (GN) combines diseases of an immuno-inflammatory nature of various etiopathogenesis with a predominant lesion of renal glomeruli. By origin, (GN) is divided into primary (actually the primary lesion of glomeruli) and secondary (developing as a result of systemic autoimmune diseases, viral hepatitis B, neoplasms). Within the framework of primary $(\mathrm{GN})$, morphological variants of glomerular damage are distinguished, such as acute diffuse proliferative (GN), rapidly progressive (extra capillary GN with the formation of crescents), membranous $\mathrm{GN}$ (membranous nephropathy -MNP), minimal change nephropathy (MCNP), focal segmental glomerulosclerosis (FSGS), membranoproliferative GN (MPGN), mesangioproliferative GN (MezPGN), MezPGN variant - IgA nephropathy, focal proliferative glomerulonephritis (FPGN), chronic diffuse proliferative GN. They can be divided into two separate groups: proliferative GN and non-proliferative. The first group includes (MezPGN), diffuse and focal proliferative GN, extra capillary GN with crescents, and (MPGN), while the second includes (MCNP), (MNP), and (FSGS). Regarding non-proliferative GN, the pathological process in the glomeruli is limited to the defeat of mainly individual layers of the glomerular filter, capillary endothelium, basement membrane, or podocytes (1) (2).

In recent years, new scientific data have been obtained on the important role of the components of natural resistance, adaptive immune response, and cytokines in the pathogenesis of $(\mathrm{GN})$, a review of which is presented in this article.

\section{The role of natural resistance factors in the pathogenesis of (GN):}

Immunological mechanisms of renal glomerular damage during the development of acute $(\mathrm{GN})$ and exacerbation of chronic (GN) are initiated by many etiological and trigger factors, such as infectious pathogens, endogenous antigens, allergens, toxicchemical substances, alcoholic excesses, hypothermia, or intravenous injections. The first to respond to microbial pathogens are cells of innate immunity, antigen-presenting cells (APC), whose Tolllike receptors (TLRs) recognize molecules of bacteria and viruses, the so-called pathogen-associated molecular patterns (PAMPs). The best-known examples of (PAMPs) are the lipopolysaccharide structures of the membranes of gram-negative bacteria, lipoproteins, lipoteichoic acids of gram-positive bacteria, viral nucleic acids, etc. [1]. (TLRs) respond not only to external pathogens but also to endogenous cellular patterns (DAMP - "dangerassociated molecular patterns") formed as a result of tissue damage (proteins, uric acid, ATP, heat shock proteins, etc.). [2]. A consequence of the TLR's response to (PAMP) and/or (DAMP) is the activation of inflammatory cells (monocytes, macrophages, granulocytes) and resident cells of the glomeruli in 
response to the pathogen [2]. A cascade of "signaltransmitting pathways" is initiated in the activated cells, causing the transcription of genes of cytokines, chemokines, NO-synthase and other regulatory mediators of inflammation, activation of the antigenpresenting function, the production of reactive oxygen species and (NO), and the formation of proinflammatory cytokines and low-molecular mediators of inflammation, causing damage to the renal glomeruli [3].

In mammals, 13 types of (TLRs) have been described. The selectivity of the (TLR) response is manifested, for example, in the fact that (TLR 2) react to the patterns of gram-positive bacteria and (TLR 4) mainly to the polysaccharides of gram-negative bacteria (4).

In the literature, many studies are associating (TLR) with (GN). Thus, a pronounced expression of (TLR4) in the renal tissue has been reported in rats with an experimentally created model of (IgA) nephropathy. At the same time, an improvement in biochemical parameters and a decrease in tubulointerstitial fibrosis were accompanied by a decrease in (TLR4) expression [4]. Studies Kimura J. and coauthors indicate a relationship between damage to podocytes of the glomerular filter in mice with autoimmune (GN) and overexpression of (TLR8) [5].

Another component of the innate immune response, the complement system, also plays an important role in the pathogenesis of (GN). The activation of the complement system during the development of (GN) can be carried out in three ways: classical, alternative, and lectin. Complement-fixing antibodies (IgG1, IgG3, $\operatorname{IgM})$ in the (IC) initiate the classical pathway of activation of complement components $(\mathrm{Clq} \rightarrow \mathrm{C} 4 \rightarrow$ $\mathrm{C} 2 \rightarrow \mathrm{C} 4 \mathrm{~b} 2 \mathrm{a} \rightarrow \mathrm{C} 3)$. Mannose-binding lectin, by binding the polysaccharide of pathogenic bacteria, triggers the lectin pathway of complement activation $(\mathrm{C} 4 \rightarrow \mathrm{C} 2 \rightarrow \mathrm{C} 4 \mathrm{~b} 2 \mathrm{a} \rightarrow \mathrm{C} 3)$. In an alternative way, activation of the key component C3 can occur spontaneously by hydrolysis of $\mathrm{C} 3$ to $\mathrm{C} 3 \mathrm{~b}$ or with the help of damaged cells, bacterial lipopolysaccharides, IgA. When C3 is cleaved by C3 convertase, components $\mathrm{C} 3 \mathrm{a}$ and $\mathrm{C} 3 \mathrm{~b}$ are formed. $\mathrm{C} 3 \mathrm{~b}$, by attaching to the $\mathrm{C} 3$ convertase, activates $\mathrm{C} 5$, which decays into $\mathrm{C} 5 \mathrm{a}$ and $\mathrm{C} 5 \mathrm{~b}$. The latter attaches the subsequent complement components - $\mathrm{C} 6, \mathrm{C} 7, \mathrm{C} 8$, and $\mathrm{C} 9$, and the membrane-attacking complex $\mathrm{C} 5 \mathrm{~b}-\mathrm{C} 9$ is formed. Activated complement components play an important role in the development of $(\mathrm{GN})$ [6]. Thus, the C5a component, which has the properties of a chemoattractant, promotes extravasation of inflammatory cells circulating in the blood (mainly neutrophils and monocytes) and their accumulation in the focus of antigen or (IC) deposition. In turn, the activated inflammatory cells release pro-inflammatory mediators that have a damaging effect on the glomeruli. The effector link of the complement system - C5b - C9 completes the immune complex reaction in situ by lysis of glomerular cells due to the formation of pores in cell membranes. In addition, C5b-9 activates resident glomerular cells to produce pro-inflammatory cytokines also involved in glomerular damage. Recent data indicate that $\mathrm{C} 5 \mathrm{a}$ can stimulate the production of pro-inflammatory cytokines by glomerular mesangial cells by activating the mitogen-activated protein kinase (MAPK) signaling pathways p38 (MAPK), (ERK 1/2), and (JNK). In particular, the activation of p38 (MAPK) stimulates the production of (IL- 6), while the activation of (ERK 1/2) and (JNK) enhances the production of (TNF- $\alpha$ ) [7].

\section{Role of cytokines in kidney damage:}

Recognition of (PAMP) or (DAMP) by (TLRs) expressed on innate immune cells triggers an intracellular activating signal leading to the initiation of a transcription factor (NF- $\kappa \beta)$. The latter determines the expression of genes for chemokines, primary proinflammatory cytokines (IL- $1, \mathrm{TNF}-\alpha$ ), and secondary pro-inflammatory cytokines (IL-6, IL-8, typeI interferons (IFN)). The resulting pro-inflammatory 
cytokines cause the development of local inflammation, as well as an acute phase response at the systemic level, aimed at the destruction and elimination of pathogenic factors. These processes involve various cells that support and regulate the inflammatory process: monocytes/macrophages, all types of granulocytes, dendritic cells, (IC) cells, epithelial cells, endothelial cells, fibroblasts, lymphocytes, etc. [8].

One of these cytokines is the pro-inflammatory cytokine (IL-1 $\beta$ ), which is the main mediator of the development of the inflammatory response and acute phase response at the systemic level [9]. The cells producing (IL-1 $\beta$ ) in the kidneys are intrarenal macrophages expressing all the necessary components of the (NLRP 3- ASC) inflammasome (an intracellular platform that ensures the conversion of IL- 1 precursor into the active form) [3]. There are data on the expression of (NLRP 3- ASC) inflammasome components and genes encoding (IL-1) on mesangial cells and podocytes $[3,10]$. It is shown that $(\mathrm{IL}-1 \beta)$, produced by leukocytes, binds to (IL-1) receptor on kidney cells and promotes the recruitment of inflammatory cells (macrophages, neutrophils) and formation of crescents in the glomeruli, while the other member of the family (IL-1) - (IL-1 $\alpha$ ) - causes the development of kidney damage of the humoral type and kidney fibrosis. Clinical studies have demonstrated a direct effect of the level of (IL-1 $\beta$ ) on the parameters associated with the inflammatory process (C-reactive protein, the number of neutrophils in the blood) and kidney damage (erythrocytes in the urine, granular casts) in patients with (GN) [11]. In the same studies, data were obtained on a positive correlation of the level of (IL-1 $\beta$ ) with the content of creatinine in the blood serum against the background of its feedback with the specific gravity of urine, which indicates a negative effect of high levels of (IL-1 $\beta$ ) on glomerular and tubular renal function.
Another representative of the "primary" proinflammatory cytokine is (TNF- $\alpha$ ), which, like (IL -1), is preferably produced by cells of the monocytemacrophage system. The production of this cytokine by mesangial cells of the glomeruli was established in the experimentally created (GN) [7, 12]. High levels of (TNF- $\alpha$ ) production have been described in children with nephrotic syndrome associated with various forms of (GN) - (FSGS), diffuse proliferative (GN), (MezPGN), (MPGN). At the same time, a positive correlation was found between the (TNF- $\alpha)$ level and proteinuria, mesangial proliferation, and glomerulosclerosis [13]. Evidence has been obtained that high concentrations of (TNF- $\alpha)$ associated with a particular allele of the gene of this cytokine (in particular, with the homozygous genotype A/A) may predispose to the development of chronic (GN) and end-stage renal failure [14].

In recent years, much attention has been paid to the study of the role of a lesser-known member of the (IL1) cytokine family - (IL-33) - in the pathogenesis of kidney disease [13]. This cytokine is a ligand for the (IL1RL1) receptor, a tumor suppressor (ST2). The results of studies have been published indicating an increase in the level of (IL-33) and the soluble form of ST2 (sST) in patients with chronic (GN) [15, 16]. Also, these same studies have shown that levels of (IL-33) did not correlate with markers of kidney damage, while (sST) shows a negative correlation with glomerular filtration rate, positive - with proteinuria and phosphorus levels in the blood.

The (IL -1) receptor antagonist (IL -1RA) can block the effects of the (IL-1) family - both (IL - $1 \alpha$ ) and (IL $1 \beta)$. This cytokine is produced mainly by neutrophils and cells of the monocytic-macrophage system. In experiments on mice, it was shown that (IL -1RA) limits kidney damage and neutrophil migration [17]. There are known data on the predominance of (IL-1 $\beta)$ production in $(\mathrm{GN})$ patients over the increase in the (IL-1 $\beta R A)$ level and on the 


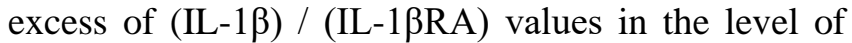
healthy people by 1.36-4.6 times, depending on the clinical variant of the disease. [11, 18].

Following the initiation of the production of (IL-1 $\beta$ ), which has specific receptors on many cells of the human body, almost all types of cells involved in the inflammatory process are activated - endothelial cells, resident macrophages of the kidneys, and almost all populations of leukocyte blood cells. In this case, (IL$1 \beta$ ) initiates the production of other cytokines (late proinflammatory) which include (IL-2), (IL- 6), and (IFN- $\gamma$ ) [19]. This is followed by the induction of the proliferative activity of regulatory T-lymphocytes $\left(\mathrm{T}_{\text {reg }}\right)$ and the production of anti-inflammatory cytokines ( IL-10, IL-4, IL-13), which are associated with the processes of repair, completion of inflammation, and return of the immune system to its normal homeostatic state [20]. The production of cytokines such as (IL-2), (IL-4), (IL-13), (IFN- $\gamma$ ) is associated with cells of adaptive immunity. Thus, IL4 and IL-13 are produced by cells of the (Th 2) / humoral component of the adaptive immune response. Van Den Berg JG . et al. in vitro studies have demonstrated the ability of (IL-4) and (IL-13) to have a damaging effect on podocytes by binding to (IL$4 \mathrm{R} 2$ ) receptors. The obtained result allowed the authors to suggest that these cytokines play an important role in the pathogenesis of specific changes in the structure of podocytes and glomerular permeability in patients with idiopathic nephrotic syndrome [21].

(IL-2) is a cytokine synthesized by helper cells - (Th 0), (Th 1), has an immunoregulatory effect on the T-system, controlling the functional (proliferative) activity of T-lymphocytes, modulating the balance of helper cells subpopulations (Th 1) / (Th 2) [22]. An increase in the level of (IL-2) in the blood serum has been described in patients with nephrotic-type GN [23]. In studies using an experimentally created (FSGS) model, on the contrary, results were obtained demonstrating the nephroprotective effect of (IL-2) [24].

(IL-10) is one of the most important regulatory cytokines in the acute inflammatory process. It inhibits the secretion of (IL-1 $\beta$ ), (IL-6), (IL-8), (IL-12), (IL23), (TNF- $\alpha),($ IFN- $\gamma$ ), as well as colony-stimulating factors, by inhibiting the expression of major histocompatibility complex antigens ( MHC) class II on activated monocytes/macrophages (25). In addition, (IL-10) stimulates (IL-1RA) production and acts as a major anti-inflammatory cytokine. (IL-10) can inhibit the cytokine-forming function of both (Th 1) cells (IL- 2, IFN $\gamma$ ) and Th 2 (IL-4, IL5) [25]. Contradictory data were obtained in experiments to study the effect of (IL-10) on mesangial proliferation. In particular, Chabdan SJ et al. showed that (IL-10) activates the proliferative activity of mesangial cells [26]. On the contrary, Kitching A. The $\mathrm{R}$. et al reported that recombinant murine (IL-10) inhibits the proliferation of mesangial cells in rats with experimentally created (MesPGN) [27]. In experimental studies on a mouse model of $(\mathrm{GN})$, the nephroprotective effect of (IL-10) was demonstrated [28]. In clinical studies, data were obtained on the negative correlation of the level of (IL$10)$ circulating in the blood of patients with $(\mathrm{GN})$ with indicators associated with the inflammatory process (the number of neutrophils in the blood, ESR, the level of $\alpha 1$-globulins) and with the serum level of creatinine [29].

$(\mathrm{IFN}-\gamma)$ is a pro-inflammatory cytokine that regulates the activity of the cellular component of the adaptive immune response. It is produced by cells of both innate and acquired immune response: natural killer cells (NK), natural killer T-cells (NKT), (Th1), and $\mathrm{CD}^{+} \mathrm{T}$-lymphocytes [30]. (IFN- $\gamma$ ) increases the phagocytic potential of macrophages and the functional activity of $\mathrm{T}$ cells, increases the expression of (MHC II) antigens on macrophages, and therefore the antigen-presenting ability of the latter, and also 
causes the differentiation of (Th0) cells into (Th1) cells, and induces apoptosis of T cells (30). Along with that, (IFN- $\gamma$ ) stimulates the production of cytokines such as (IL-1 $\beta)$, (IL-6) and (TNF- $\alpha$ ) [31]. It has been shown that certain low concentrations of (IFN- $\gamma$ ) in the experiment can inhibit the pathogenic effect of (IgG3)cryoglobulins and prevent the deposition of the (C3) component of the complement system in the capillaries of the glomeruli [32]. Opposite results were obtained in other experimental studies demonstrating the pathogenetic significance of (IFN- $\gamma)$ in the development of a diffuse proliferative variant of GN [33].

The role of the adaptive immune response in the development of (GN):

An important role in the development of damage to glomeruli of specific $\mathrm{CD} 4^{+}-\mathrm{T}$ cells is known. Differentiation of naive $\left(\mathrm{CD} 4^{+}\right)$-helper cells and the direction of development of the adaptive immune response, by cellular or humoral type, depends on the prevailing cytokine environment ( IL-2, IL4, IL-5, IL-6, IL-12, IL-13, IL- 17) and transforming growth factor- $\beta$ (TGF- $\beta$ ) [34]. Isolation of four lines $\left(\mathrm{CD} 4^{+}\right)$- $\mathrm{T}$ cells, particularly effector cells ( $\left.\mathrm{T}_{\text {eff }}\right)$ (Th1, Th2, Th17) and regulatory cells $\left(\mathrm{T}_{\text {reg }}\right)$, is based on the identification of antigens expressed on their surface (cluster differentiation markers - CD ), lineage-specific transcription factors ( Foxp 3, T-bet ), and cytokine genes ( IFN- $\gamma$, IL-4, IL10, IL-17) [35].

(IL-12) directs the differentiation of naive (Th0) cells along the pathway of transformation into (Th1) cells (CD $4^{+}$, IFN- $\gamma$ ), participating in the development of T-cell-macrophage-mediated reactions of the type of delayed-type hypersensitivity (DTH). The formation of (Th17) cells is facilitated by the presence of cytokines - (IL-6, IL-17). The cells of this subpopulation of T-helper cells produce (IL17a) and (IL-21), which ensure the activation of resident macrophages in the glomeruli and the recruitment of other inflammatory cells (monocytes, neutrophils, platelets). In addition, (Th17) cells can directly damage the renal glomeruli. In the presence of transforming growth factor- $\beta$ (TGF$\beta),\left(\mathrm{T}_{\text {reg }}\right)$ $\left(\mathrm{CD} 4{ }^{+} \mathrm{CD} 25^{+}\right.$FoxP $\left.3{ }^{+}\right)$are formed from $\left(\mathrm{CD} 4^{+}\right)$cells, which inhibit the immune response $\left(\mathrm{T}_{\text {eff }}\right)$ and renal damage [35, 37].

Under conditions of the predominance of the production of (IL-2), (IL-4), (IL-13) from (Th0) cells, (Th2) cells (CD $\left.4{ }^{+}, \mathrm{IL}-4\right)$ are formed and reactions of the type of immediate hypersensitivity develop with the participation of (IgE) and eosinophils [36]. (Th2) stimulates B-cells and plasma cells to produce specific antibodies that can be involved in the formation of immune complexes (IC) causing damage to glomeruli. Half a century ago, in an experiment on rabbits with serum sickness, it was shown that the deposition of circulating (ICs) containing antigen and ( $\operatorname{IgG})$ in the glomeruli has a damaging effect on the glomeruli of the kidneys [38]. As a result of another study, evidence was obtained that (ICs) deposits activate the complement system by the classical pathway with the formation of the chemotactic factor (C5a) among the intermediate components of the complement. The latter attracts circulating inflammatory cells that cause damage to the glomeruli [39].

Three possible mechanisms of the formation and deposition of (ICs) in the glomeruli during the development of $(\mathrm{GN})$ have been described. So, in the glomeruli, circulating (ICs), which are formed, as is known, under conditions of a certain excess of antigens, can be passively retained and deposited. In this case, (ICs) appear in the sub-endothelial and mesangial spaces, where they form larger (ICs) gratings, visible under a luminescent microscope (36). (ICs) can be formed in situ. There are two types of (ICs) formation in situ. The formation of the first type of (ICs) involves circulating antigens entering the glomeruli, which at the initial phase of the process are 
located in the sub-endothelial and mesangial spaces (large antigens) or the sub-epithelial space under podocytes (small antigens); then free antibodies are attached to these antigens and antigen-antibody complexes are formed. In the second type of (ICs) formation, autoantibodies to unchanged glomerular structures are formed in situ. The method of formation of (ICs), biological properties of immunoglobulins included in the (ICs) (degree of activation of the complement system, affinity of the $\mathrm{Fc}$-receptor, severity of cryoprecipitation), the location of the (ICs) in various structures of the renal glomeruli and the concentration of (ICs) affect the nature of clinical manifestations of (GN). In particular, sub-endothelial (ICs) lead to the development of exudative inflammation of the glomeruli. (ICs) deposits in the mesangium cause the proliferation of mesangial cells with the expansion of the mesangial matrix. With subepithelial (ICs) deposition, non-inflammatory damage to podocytes associated with their fusion occurs, while pronounced proteinuria is observed. The formation of (ICs) in situ induces local tissue damage in the kidneys, while in the case of secondary deposition of circulating (ICs) in the glomeruli, the nephritogenic effect of (ICs) is not observed. As for the concentration of (ICs), as it increases, the disease becomes worse [36].

The degree of involvement of the described immunological mechanisms in the pathogenesis of (GN) varies significantly depending on the clinical and morphological variant of the disease.

Immunopathological features of the main clinical and morphological variants of (GN):

\section{Minimal change nephropathy (MCNP):}

Experiments and clinical studies have shown that (MCNP) is an immune-mediated pathology of glomeruli, which is based on the activation of (Th2) cells with the development of an adaptive immune response of the humoral type - the immediate hypersensitivity reaction. At the same time, (IL-4) and (IL-13) produced by (Th2) cells cause damage to podocytes $[21,36,40]$. The decrease in the content of $\left(\mathrm{T}_{\mathrm{reg}}\right)$ circulating in the peripheral blood, found in patients with steroid-resistant (MCNP), suggested that the pathogenesis of treatment-resistant (MCNP) cases is associated with an imbalance in the balance of immunoregulatory subpopulations of $\left(\mathrm{CD} 4^{+}\right)$helper cells towards $\left(\mathrm{T}_{\text {eff }}\right)$ predominance [41].

\section{Membranous nephropathy (MNP):}

The development of (MNP) is associated with the polarization of the adaptive immune response towards the prevalence of (Th2) / humoral link and subepithelial deposition of (ICs), consisting of autoantibodies (mainly IgG 4), autoantigens, and complement (42). Two different antigens were recognized in the (ICs). One of them (neutral endopeptidase) is involved in the development of (MNP) in newborns [43], the other, the M-type phospholipase A2 receptor (PLA2R "phospholipase A 2 receptor "), is found in adult patients with (MNP). (PLA2R) is expressed on podocytes and, upon binding to circulating anti- (PLA2R) autoantibodies, forms subepithelial (IC) deposits in situ [44]. In this case, damage to podocytes is mediated by the activation of complement with the formation of a membrane-attacking complex (C5bC9) [42]. (IgG 4) molecules, which are part of the (ICs), are not able to activate complement by the classical pathway. They bind mannose-binding lectin and initiate the lectin pathway for complement activation. Stanescu H.C . et al. and other authors identified alleles in the (PLA2R1) and (HLA - DQA1) loci associated with the development of (MNP) [45], which indicates the dependence of the development of (MNP) on genetic factors.

\section{Focal segmental glomerulosclerosis (FSGS):}

Lordan S.C. and co-authors formulated the position on the key role in the development of (FSGS), activation of the cellular component of the adaptive immune response [23] was developed in the studies of 
other authors [44]. An increase in the number of $\left(\mathrm{CD}^{+}\right)$-T cells, an increase in the expression of the (IL2) receptor $(\mathrm{CD} 25)$ on $\left(\mathrm{CD} 4^{+}\right)$cells, a predominance of (CD3) expression on the cells of nephron biopsy specimens of (FSGS) patients [46], as well as an increase in the content of (Th17) cells in the peripheral blood [47] have been shown. It was demonstrated in vitro that (IL-17) produced by (Th17) cells induces apoptosis of podocytes [47].

Data on the participation of pro-inflammatory cytokines - (TNF- $\alpha)$, (IL-1 $\beta)$, and (TGF- $\beta 1)$ in the pathogenesis of (FSGS) are presented [48]. In the nephron biopsy specimens of patients with (FSGS), an increased expression of the (IL-1 $\beta$ ) and (TGF- $\beta 1)$ genes was found. Increased levels of (IL-2), (IL-4), (IL$6)$, (IL-10), and (IFN- $\gamma$ ) were found in the urine of patients [49].

\section{Acute diffuse proliferative (GN):}

The development of acute diffuse proliferative (GN) is associated with an infection of extrarenal localization (streptococci, staphylococci, viruses, parasites), which triggers immunocomplex damage to the glomeruli with the participation of the (C3) component of complement and (IgG). In this case, (ICs) can appear in the glomeruli due to the deposition of circulating (ICs) or are formed in situ [36]. All known ways of activating the complement system are possible $[6,50]$. For the considered form of (GN), the following histopathological features are inherent:

1) Diffuse endo-capillary proliferative (GN) (detected by light microscopy).

2) Deposits in the wall of the glomerular capillaries of the (C3) component of the complement or deposits of the immune complex, consisting of (C3) and immunoglobulins, mainly (IgG) (found during immunohistochemical examination).

3) Hump-like deposits in the sub-epithelial space, which can occur in isolation or parallel with subendothelial, mesangial, and intramembranous deposits (established by electron microscopy) [51].

\section{Extracapillary (GN) with the formation of} crescents:

Extracapillary (GN) with the formation of crescents is distinguished as a rapidly progressive (GN), characterized by an aggressive course with the development of the nephritic syndrome and with the formation in most cases within three months of irreversible renal failure [52]. The key point in the pathomorphological processes occurring in this glomerulopathy is the extra capillary proliferation of monocytes/macrophages, fibroblasts, parietal epithelial cells, spreading to more than half of the renal glomeruli (52). Moreover, in the cells of the monocytemacrophage series, an increased expression of the genes of pro-inflammatory cytokines - (IL-1 $\beta$ ) and (TNF- $\alpha)$ is found. It has been shown that the production of (IL-1 $\beta$ ) is carried out mainly by macrophages contained in crescents. The interaction of (IL-1 $\beta$ ) with specific receptors I (IL- $1 \mathrm{RI}$ ) on glomerular cells leads to the generation of a signal that initiates the expression of (TNF- $\alpha$ ) genes on the same cells, as well as on epithelial cells of the tubules. (TNF$\alpha$ ), being formed in excess amounts, when attached to the corresponding specific receptors, induces cell apoptosis and damage to the glomeruli. Formed from monocytes macrophages, fibroblasts, parietal epithelial cells form a "cellular" half-moon, which squeezes the capillaries of the glomeruli, impedes or blocks the formation of urine with the development of oligoanuria. As a result of the progression of the process, the crescent moon becomes fibrotic and the glomeruli are completely hardened. The mechanisms of the pathogenesis of extra capillary (GN) with the formation of crescents described above are realized under conditions of an imbalance of immunoregulatory subpopulations of $\left(\mathrm{CD}^{+}\right)$cells associated with the predominance of $\left(\mathrm{T}_{\text {eff }}\right)-(\mathrm{Th} 1)$ and $(\mathrm{Th} 17)$ [35, 37].

\section{Mesangioproliferative (GN) (MezPGN):}

The pathological picture during the development of (MesPGN) consists of the proliferation of endothelial 
and mesangial cells of the glomeruli; deposits of ( $\operatorname{Ig} \mathrm{A})$, (IgM), (IgG), (C3), and (C4) in the mesangium. Depending on which class of immunoglobulins is predominant in glomerular deposits, three variants of (MezPGN) are distinguished - (IgA-MezPGN), (IgM-MezPGN), and (IgGMezPGN). In some cases, with (MezPGN), there are no deposits of immunoglobulins. The most common among all forms of (GN), including (MezPGN), is (IgA-MezPGN) (IgA nephropathy) [53].

\section{(IgA) nephropathy (Berger's disease):}

(IgA) nephropathy is characterized by diffuse deposits of $(\operatorname{Ig} \mathrm{A})$ in the mesangium, often in combination with (IgG) or with (IgM), (C3) component, and (C5b9) complex. An exacerbation of the disease is provoked by upper respiratory tract infections, in which the formation of ( $\operatorname{Ig} \mathrm{A})$ increases (54). According to one of the main hypotheses of the pathogenesis of this glomerular pathology, (ICs) are deposited in the mesangial space as a result of a delay in circulating (ICs), which contain abnormal immunoglobulin -(Gd-IgA1) (galactose-deficient $\operatorname{IgA} 1)$. The molecule of the latter has a defect in heavy chains in the region of the hinge regions due to a violation of their glycosylation. This disruption in the (Gd-IgA1) molecule leads to the exposure of antigenic determinants and imparts autoantigenic properties to the molecule, causing the formation of (IgG) or (IgA1) antiglycan antibodies. Subsequently, "nephritogenic" ICs are formed, consisting of (Gd-IgA1) and antiglycan antibodies [54]. (Gd-IgA1)-containing (ICs) cause activation of the complement system by an alternative pathway, and also activate resident mesangial cells, their production of pro-inflammatory cytokines and growth factors that cause proliferation and excess production of extracellular matrix, damage to the renal glomeruli, and the development of chronic $(\mathrm{GN})$. According to the data from Novak $\mathrm{J}$. and coauthors, aberrant ( $\mathrm{Gd}-\operatorname{IgA} 1)$ is formed by (IgA1)- secreting cells, which have a genetically determined disorder of the activity of the specific enzyme, glycosyltransferase [54]. According to other researchers, the level of $(\mathrm{Gd}-\operatorname{IgA} 1)$ production is associated with the formation of pro-inflammatory cytokines during infectious processes in the upper respiratory tract. It has been shown that (IL-6) deactivates the key enzymes that provide glycosylation of (IgA1)-specific glycosyltransferases - (C1GalT1) and (ST6GalNAc-II) and, therefore, causes an increase in the level of (Gd-IgA1) and circulating "nephritogenic" (ICs) containing pathological immunoglobulin [55]. The clinical manifestation of (IgA) nephropathy is very variable - from subclinical forms to severe, occurring with the development of end-stage renal failure. New data have been obtained indicating that the selective deposition of the $(\mathrm{C} 4 \mathrm{~d})$ component of complement in the absence of deposits of immunoglobulins and (IC), directs the activation of the complement system along the lectin pathway and determines the more severe course of ( $\operatorname{Ig} \mathrm{A})$ nephropathy, manifested by hyperproteinuria, systemic hypertension, increased serum creatinine levels, reduced rate of filtration by the time of disease manifestation [56].

\section{Post-streptococcal GN (PSGN), post-infectious GN (PIGN):}

Proliferative forms of (GN) are manifested mainly as (PSGN), which is currently considered as (PIGN), which affects persons with foci of streptococcal infection in the upper respiratory tract (tonsillitis, pharyngitis, scarlet fever) [57]. In modern conditions, (PIGN) is found mainly among children living in countries with a low level of socio-economic development. In recent decades, (PIGN) has also spread among adults in European and North American countries.

(PIGN) in children in the predominant number of cases is caused by nephritogenic strains of streptococci and is manifested by morphological signs of diffuse 
endocapillary proliferative (GN), less often exudative (GN). Morphological examination of the nephron biopsy using the immunofluorescence method reveals diffuse deposits of (C3) and often (IgG) [58]. Clinical manifestations usually develop 2 weeks after the infection. During this period, there is the production of specific antibodies to infectious antigens, the formation and deposition of (ICs) in the glomeruli. The key link in the pathogenesis of (PIGN) is the activation of the complement system involving all its possible pathways - classical, alternative, and lectin, in which (C1), (C3), (C4) components, mannose-binding lectin, and properdin are involved [6, 50]. It is believed that only nephritogenic strains of Streptococcus pyogenes (types 1, 2, 4, 12, 18, 25, $49,55,57,60)$ are capable of causing the development of (PIGN). In recent years, much attention is given to the pathogenetic role of two streptococcal antigens: nephritis-associated plasmin receptor and streptococcal pyogenic exotoxin B [57].

In adults, (PIGN) is more often caused by an infection of staphylococcal origin (infections of the oropharynx, nasopharynx, urogenital tract, pneumonia, osteomyelitis, pyoderma, etc.) $[57,58]$. Most cases of post-staphylococcal (GN) are associated with infection caused by Staphylococcus (S) aureus, more often methicillin-resistant strains. Gram-negative microorganisms (Escherichia

coli, Yersinia, Pseudomonas, and Haemophilus) are responsible for the development of (PIGN) in about $10 \%$ of cases. Cases of (PIGN) caused by mycoplasma pneumonia, causative agents of scabies, tuberculosis have been described [59, 60]. (PIGN) in adults can manifest itself in various variants of proliferative $(\mathrm{GN})$. In this case, $(\operatorname{Ig} \mathrm{A})$ deposits prevail in the glomeruli [60]. The IgA dominant form of (PIGN) should be differentiated from (IgA)- nephropathy. In contrast to the latter, with the $\operatorname{IgA}$ dominant form of (PIGN), all signs of endocapillary (GN) with subepithelial deposits in the form of humps and hypocomplementemia are found. Post-staphylococcal (GN) mainly occurs in persons over 60 years with a weakened immunoreactivity with chronic foci of infection, diabetes mellitus, alcoholism, the use of cytostatics, and others. The average duration of the period from the moment of infection to kidney damage is 4 weeks. The pathogenetic mechanisms contributing to the selective deposition of $(\operatorname{Ig} \mathrm{A})$ in the glomeruli in patients with post-staphylococcal (GN) are not fully understood. It is believed that some antigens of $S$. aureus (for example, enterotoxins $B$ and $C$ ) have the properties of superantigens that can directly bind to APC class II histocompatibility antigens and activate them to massive production of proinflammatory cytokines, (IgG) and (IgA) [57].

Evidence has also been obtained on the pathogenetic significance of the predominance of $\left(\mathrm{T}_{\text {eff }}\right)-\mathrm{Th} 1$ and Th17 activity in the development of PIGN [35, 37].

\section{Conclusion}

To date, the literature presents data on the important role of infection as an initiating component of the immunopathogenesis of (GN). Macrophages and dendritic cells are the first to respond to infections, recognizing infectious pathogens using (TLRs). The activation of the latter causes an intracellular cascade of reactions that determine the production of growth factors and cytokines. The predominant type of cytokine environment determines the mechanism of activation of the adaptive immune response during the development of (GN). It was shown that both cellular and humoral components of adaptive immunity can participate in the immunopathogenesis of $(\mathrm{GN})$. The role of (TLR) dysfunction in the development of (GN) is undeniable, but to date, there is little data on the significance of specific types of these receptors in the implementation of immunopathological mechanisms of various forms of glomerular pathology.

Conflict of interest: The authors declare no conflict of interest.

Funding: The study had no sponsorship. 


\section{References}

1. Chandler C.E., Ernst R.K. Bacterial lipids: powerful modifiers of the innate immune response. F1000Research. 2017; 6: F1000 Faculty Rev-1334. Doi:10.12688/f1000research. 11388.1.

2. Álvarez K., Vasquez G. Damage-associated molecular patterns and their role as initiators of inflammatory and auto-immune signals in systemic lupus erythematosus. Int. Rev. Immunol. 2017; 36(5): 259-270. Doi: 10.1080/08830185.2017.1365146.

3. Anders H.J. Of Inflammasomes and Alarmins: IL$1 \beta$ and IL- $1 \alpha$ in Kidney Disease. J. Am. Soc. Nephrol. 2016; 27(9): 2564-75. Doi: 10.1681/ASN.2016020177. 4. Chen X., Peng S., Zeng H., Fu A., Zhu Q. Toll-like receptor 4 is involved in a protective effect of rhein on immunoglobulin A nephropathy. Indian Journal of Pharmacology. 2015; 47(1): 27-33. Doi:10.4103/02537613.150319.

5. Kimura J., Ichii O., Miyazono K., Nakamura T., Horino T., Otsuka-Kanazawa S. et al. Overexpression of Toll-like receptor 8 correlates with the progression of podocyte injury in murine autoimmune glomerulonephritis. Scientific Reports. 2014; 4: 7290. Doi:10.1038/srep07290.

6. Bomback A.S., Markowitz G.S., Appel G.B. Complement-Mediated Glomerular Diseases: A Tale of 3 Pathways Kidney Int. Rep. 2016; 1(3): 148-155. Doi: 10.1016/j.ekir.2016.06.005.

7. Ji M., Lu Y., Zhao C., Gao W., He F., Zhang J. et al. C5a Induces the Synthesis of IL-6 and TNF- $\alpha$ in Rat Glomerular Mesangial Cells through MAPK Signaling Pathways. PLoS One. 2016; 11(9): e0161867. Doi: 10.1371/journal.pone.0161867.

8. Liu Q., Ding J.L. The molecular mechanisms of TLR-signaling cooperation in cytokine regulation. Cell. Biol. 2016; 94(6): 538-42. Doi:10.1038/icb.2016.18

9. Ito Y., Kaneko N., Iwasaki T., Morikawa S., Kaneko K., Masumoto J. IL-1 as a target in inflammation. Endocr. Metab. Immune Disord. Drug Targets. 2015;
15(3):

206-11.

Doi: $10.2174 / 1871530315666150316123657$.

10. Shahzad K., Bock F., Dong W., Wang H., Kopf S., Kohli S. et al. Nlrp3-inflammasome activation in nonmyeloid-derived cells aggravates diabetic nephropathy. Kidney $\quad$ Int. $\quad 2015 ; \quad$ 87(1): 74-84. Doi:10.1038/ki.2014.271

11. Karzakova L.M., Avtonomova O.I., Kudryashov S.I., Komelyagina N.A., Ukhterova N.D. The role of circulating cytokines and thyroid hormones in the development of the nephrotic variant of glomerulonephritis. [Pathological Physiology and Experimental Therapy]. 2016; 60 (3): 76-82. (in Russian)

12. Shilov E.M. Immunological mechanisms of development of nephrites. [Nephrology]. 1995; 1: 125. (in Russian)

13. Bakr A., Shokeir M., El-Chenawi F., El-Husseni F., Abdel-Rahman A., El-Ashry R. Tumor necrosis factor-alpha production from mononuclear cells in nephrotic syndrome. Pediatr. Nephrol. 2003; 18(6): 516-20.

14. Prakash S., Sarangi A.N., Tripathi G., Sharma R.K., Agrawal S. Prediction of susceptible biomarkers for end-stage renal disease among North Indians. Nephrology (Carlton). 2016; 21(7): 592-600. Doi: 10.1111/nep. 12635 .

15. Chen W.Y., Li L.C., Yang J.L. Emerging Roles of IL-33/ST2 Axis in Renal Diseases. Int. J. Mol. Sci. 2017; 18(4): E783. Doi: 10.3390/ijms 18040783.

16. Zhang Z., Wang H., Zhang L., Crew R., Zhang N., Liu X., Jiang Y. Serum Levels of Soluble ST2 and IL-10 Are Associated with Disease Severity in Patients with IgA Nephropathy. Immunol Res. 2016; 2016:6540937. Doi:10.1155/2016/6540937.

17. Furuichi K., Wada T., Iwata Y., Kokubo S., Hara A., Yamahana J. et al. Interleukin-1-dependent sequential chemokine expression and inflammatory cell infiltration in ischemia reperfusion injury. Crit. 
Care Med. 2006; 34(9): 2447-55. Doi: diseases. Neuropharmacology. 2015; 96(Pt A): 55-69. 10.1097/01.CCM.0000233878.36340.10

Doi:10.1016/j.neuropharm.2014.10.020.

18. Karzakova L.M., Avtonomova O.I., Kudryashov

26. Chadban S.J., Tesch G.H., Foti R., Lan S.I., Komelyagina N.A., Gavrilova E.S., Lutkova T.S. To the question of the glomerulonephritis pathogenesis with the isolated uric syndrome. [Modern problems of science and education]. 2016; 4: 114. (in Russian)

19. De Groote D., Zangerle P.F., Gevaert Y., Fassotte M.F., Beguin Y., Noizat-Pirenne F. et al. Direct stimulation of cytokines (IL-1 beta, TNF-alpha, IL-6, IL-2, IFN-gamma and GM-CSF) in whole blood. I. Comparison with isolated PBMC stimulation. Cytokine. 1992; 4 (3): 239-48.

20. Caramalho I., Lopes-Carvalho T., Ostler D., Zelenay S., Haury M., Demengeot J. Regulatory T Cells Selectively Express Toll-like Receptors and Are Activated by Lipopolysaccharide. The Journal of Experimental Medicine. 2003; 197(4): 403-11. Doi:10.1084/jem.20021633.

21. van Den Berg J.G., Weening J.J. Role of the immune system in the pathogenesis of idiopathic nephrotic syndrome. Clin. Sci. (Lond). 2004; 107(2): 125-36.

22. Ehlers S., Smith K.A. Differentiation of $\mathrm{T}$ cell lymphokine gene expression: the in vitro acquisition of T cell memory J. Exp. Med. 1991; 173(1): 25-36.

23. Jordan S.C., Querfeld S.U., Toyoda M., Prehn J. Serum interleukin-2 levels in a patient with focal segmental glomerulosclerosis. Relationship to clinical course and cyclosporin A therapy. Pediatr. Nephrol. 1990; 4(2): 166-8.

24. Polhill, T., Zhang, G. Y., Hu, M., Sawyer, A., Zhou, J. J., Saito, M. et al. IL-2/IL-2Ab complexes induce regulatory $\mathrm{T}$ cell expansion and protect against proteinuric CKD. J. Am. Soc. Nephrol. 2012; 23(8): 1303-8. Doi: 10.1681/ASN.2011111130.

25. Kwilasz A.J., Grace P.M., Serbedzija P., Maier S.F., Watkins L.R. The therapeutic potential of interleukin-10 in neuroimmune

H.Y., Atkins R.C., Nikolic-Paterson D.J. Interleukin10 differentially modulates MHC class II expression by mesangial cells and macrophages in vitro and in vivo. Immunology. 1998; 94(1): 72-8.

27. Kitching A.R., Katerelos M., Mudge S.J., Tipping P.G., Power D.A., Holdsworth S.R. Interleukin-10 inhibits experimental mesangial proliferative glomerulonephritis. Clin Exp. Immunol. 2002; 128(1): 36-43.

28. Ostmann A., Paust H.J., Panzer U., Wegscheid C., Kapffer S., Huber S. et al. Regulatory T cellderived IL-10 ameliorates crescentic GN. J. Am. Soc. Nephrol. 2013; 24(6): 930-42. Doi: 10.1681/ASN.2012070684.

29. Karzakova L.M., Avtonomova O.I., Stepanova I.M., Komeliagina N.A., Kudriashov S.I.

The characteristics of cytokine status under different clinical variants of glomerulonephritis Klin. Lab. Diagn.[ Klin. Lab. Diagn.] 2015; 60(6): 33-6. (in Russian)

30. Rutishauser R.L. Kaech SM. Generating diversity: transcriptional regulation of effector and memory CD8 T-cell differentiation. Immunol. Rev. 2010; 235(1): 219-33. DOI: 10.1111/j.0105-2896.2010.00901.x.

31. Murali-Krishna K., Altman J.D., Suresh M., Sourdive D.J., Zajac A.J., Miller J.D. et al. Counting antigen-specific CD8 T cells: a reevaluation of bystander activation during viral infection. Immunity. 1998; 8(2): 177-87.

32. Haas C., Ryffel B., Le Hir M. IFN-gamma is essential for the development of autoimmune glomerulonephritis in MRL/Ipr mice. $J$. Immunol. 1997; 158(11): 5484-91.

33. Okamoto A., Fujio K., Tsuno N.H., Takahashi K., Yamamoto K. Kidney-infiltrating CD4+ T-cell clones promote nephritis in lupus-prone mice. Kidney Int. 2012; 82(9): 969-79. Doi: 10.1038/ki.2012.242. 
34. Tipping PG, Holdsworth SR. T cells in crescentic glomerulonephritis. J. Am. Soc. Nephrol. 2006; 17(5):1253-63. Doi: 10.1681/ASN.2005091013.

35. Yang C., Huang X-R, Fung E, Liu H-F, Lan H-Y. The Regulatory T-cell Transcription Factor Foxp3 Protects against Crescentic Glomerulonephritis. Sci. Rep. 2017; 7(1):1481. Doi: 10.1038/s41598-01701515-8.

36. Couser W.G. Basic and Translational Concepts of Immune-Mediated Glomerular Diseases J. Am. Soc. Nephrol. $\quad 2012 ; \quad 23(3): \quad 381-99 . \quad$ Doi: 10.1681/ASN.2011030304.

37. Hall B.M. T Cells: Soldiers and Spies-The Surveillance and Control of Effector $\mathrm{T}$ Cells by Regulatory T Cells. Clin. J. Am. Soc. Nephrol. 2015; 10(11): 2050-64. Doi: 10.2215/CJN.06620714.

38. Wilson C.B., Dixon F.J. Diagnosis of immunopathologic renal disease. Kidney Int. 1974; 5(6): 389-401.

39. Cochrane C.G., Koffler D. Immune complex disease in experimental animals and man. $A d v$. Immunol. 1973; 16(0): 185-264.

40. Akdis M. , Akdis C.A., Weigl L., Disch R., Blaser K.. Skin-homing, CLA+ memory T cells are activated in atopic dermatitis and regulate IgE by an IL-13dominated cytokine pattern: IgG4 counter-regulation by CLA-memory T cells. J. Immunol. 1997; 159(9): 4611-9.

41. Jaiswal A., Prasad N., Agarwal V., Yadav B., Tripathy D., Rai M. et al. Regulatory and effector T cells changes in remission and resistant state of childhood nephrotic syndrome. Indian $J$. Nephrol. 2014; 24(6): 349-55. Doi: 10.4103/09714065.132992.

42. Sinico R.A., Mezzina N., Trezzi B., Ghiggeri

G.M., Radice A. Immunology of membranous nephropathy: from animal models to humans. Clin. Exp. Immunol. 2016; 183(2):157-65. Doi: 10.1111/cei.12729.
43. Debiec H., Guigonis V., Mougenot B., Haymann J.P., Bensman A., Deschênes G., Ronco P.M. Antenatal membranous glomerulonephritis due to anti-neutral endopeptidase antibodies. N. Engl. J. Med. 2002; 346(26): 2053-60.

44. Beck L.H. Jr, Bonegio R.G., Lambeau G., Beck D.M., Powell D.W., Cummins T.D. et al. M-type phospholipase A2 receptor as target antigen in idiopathic membranous nephropathy. N. Engl. J. Med. 2009; 361(1): 11-21. Doi: 10.1056/NEJMoa0810457.

45. Stanescu H.C., Arcos-Burgos M., Medlar A., Bockenhauer D., Kottgen A., Dragomirescu L. et al. Risk HLA-DQA1 and PLA (2) R1 alleles in idiopathic membranous nephropathy. N. Engl. J. Med. 2011; 364(7): 616-26. Doi: 10.1056/NEJMoa1009742.

46. Benz K., Büttner M., Dittrich K., Campean V., Dötsch J., Amann K. Characterisation of renal immune cell infiltrates in children with nephrotic syndrome. Pediatr. Nephrol. 2010; 25(7): 1291-8. Doi: 10.1007/s00467-010-1507-0.

47. Wang L., Li Q., Wang L., Li C., Yang H., Wang X., Tao H. The role of Th17/IL-17 in the pathogenesis of primary nephrotic syndrome in children. Kidney and Blood Pressure Research. 2013; 37(4-5): 332345. Doi: 10.1159/000350161.

48. Kronbichler A., Leierer J., Oh J., Meijers B., Shin J. Immunologic Changes Implicated in the Pathogenesis of Focal Segmental Glomerulosclerosis. Biomed. Res. Int. 2016; 2016: 2150451. Doi: 10.1155/2016/2150451.

49. Kalavrizioti D., Gerolymos M., Rodi M., Kalliakmani P., Provatopoulou S., Eleftheriadis T. et al. T helper (Th)-cytokines in the urine of patients with primary glomerulonephritis treated with immunosuppressive drugs: can they predict outcome? Cytokine. 2015; 76(2): 260-9. Doi: 10.1016/j.cyto.2015.08.002.

50. Vernon K.A., Goicoechea de Jorge E., Hall A.E., Fremeaux-Bacchi V., Aitman T.J., Cook H.T. et al. 
Acute presentation and persistent glomerulonephritis following streptococcal infection in a patient with heterozygous complement factor H-related protein 5 deficiency. Am. J. Kidney Dis. 2012; 60(1): 121-5. Doi: 10.1053/j.ajkd.2012.02.329

51. Satoskar A.A., Nadasdy T., Silva F.G. Acute postinfectious glomerulonephritis and glomerulonephritis caused by persistent bacterial infection In: Jennette J.C., Olson J.L., Silva F.G., D'Agati V.D., eds. Heptinstall's Pathology of the Kidney. 7th Ed. Philadelphia, PA: Wolters Kluwer; 2015: 367-436.

52. Moroni G., Ponticelli C. Rapidly progressive crescentic glomerulonephritis: Early treatment is a must. Autoimmun. Rev. 2014; 13(7): 723-9. Doi: 10.1016/j.autrev.2014.02.007.

53. Varshavskiy V.A., Proskurneva E.P., Gasanov A.B., Severgina L.O., Shestakova L.A. About specification of clinical and morphological classification of chronic glomerulonephritis. [Nephrology and dialysis] 1999; 1(2-3): 100-6. (in Russian)

54. Novak J., Julian B.A., Mestecky J., Renfrow M.B. Glycosylation of $\operatorname{IgA} 1$ and pathogenesis of $\operatorname{IgA}$ nephropathy. Semin Immunopathol. 2012; 34(3): 36582. Doi: 10.1007/s00281-012-0306-z.

55. Suzuki H., Raska M., Yamada K., Moldoveanu Z., Julian B.A., Wyatt R.J. et al. Cytokines alter IgA1
O-glycosylation by dysregulating C1GalT1 and ST6GalNAc-II enzymes. J. Biol. Chem. 2014; 289(8): 5330-9. Doi: 10.1074/jbc.M113.512277.

56. Wągrowska-Danilewicz M., Danilewicz M. The utility of glomerular $\mathrm{C} 4 \mathrm{~d}$ immunostaining in renal biopsies in patients with immunoglobulin A nephropathy. A clinicopathological study. Pol. J. Pathol. 2017; 68 (2): 148-152. DOI: https://doi.org/10.5114/pjp.2017.69691.

57. Kanjanabuch T., Kittikowit W., Eiam-Ong S. An update on acute postinfectious glomerulonephritis worldwide. Nat. Rev. Nephrol. 2009; 5: 259-69.

58. Nasr S.H., Radhakrishnan J., D'Agati V.D. Bacterial infection-related glomerulonephritis in adults. Kidney Int. 2013; 83(5): 792-803. Doi: 10.1038/ki.2012.407.

59. Chen X., Xu W., Du J., Wang H. Acute postinfectious glomerulonephritis with a large number of crescents caused by Mycoplasma pneumoniae. Indian J. Pathol. Microbiol. 2015; 58(3): 374-6. DOI: 10.4103/0377-4929.162907.

60. Anand M., Arroyo J.P., Alhalabi H., Thayer T., Lusco M., Langone A., Concepcion B.P. IgADominant Acute Postinfectious Glomerulonephritis Presenting as Acute Renal Failure in a Kidney Transplant Recipient. Kidney Int. Rep. 2017; 2(4): 7669. DOI: 10.1016/j.ekir.2017.01.011. 